\title{
The Lean Management of Spare Parts in Automotive Manufacturing
}

\author{
Guo Dongdong ${ }^{1}$,Yu Xingwu ${ }^{2}$ \\ ${ }^{1}$ No.8 Boxing Road, Economic Technological Development Area (BDA), Beijing, China \\ ${ }^{2}$ No. 8 Boxing Road, Economic Technological Development Area (BDA), Beijing, China
}

\begin{abstract}
Spare part management is one of the most important work for enterprises, especially for manufacturing enterprises; however, the spare part management problems trouble enterprise operators a lot. In this article, implementation methods of lean spare parts management are illuminated. Spare parts purchase process is declared to reduce the purchasing cost and inventory value. We had established a suitable lean spare parts inventory management model for consumable parts, wear parts, insurance parts and accident parts. In addition, methods of lean spare parts management had been created base on optimized supply chain, ERP and integrating repeated material inventory. We used SAP-iPro system and self-developed system to manage spare parts, so that warehouse management process, spare parts purchase process and maintenance process are standardized. According to theory analysis and practice, the remarkable economic benefit is created for enterprise by the means of optimizing spare parts distribution, standardizing and scientific spare parts management.
\end{abstract}

\section{Introduction}

Nowadays, a higher level for the normal operation of production equipment has been required in the field of automotive manufacturing with the increasingly severe competition in the global market. There is no doubt that the downtime caused by equipment failure will bring huge losses to the enterprise. As a kind of indispensable supply for equipment maintenance, it is quite significant to keep enterprise's spare part inventory within a certain reasonable quantity [1]. Therefore, implementing scientific management for spare parts in the aspects of procurement, delivery date, warehouse maintenance, inventory control, allocation and so on will play an important role in the equipment maintenance work.

However, the surplus spare parts stock due to improper management will increase the operation cost of the enterprise. According to statistics, the spare parts inventory fund usually occupies about $7 \%$ of the total corporate liquidity. It has been identified that high cost of spare parts inventory has become the most troublesome problem in controlling the manufacturing production cost and production efficiency [2]. At present, in order to ensure the scientific purchasing and reduce the stock funds effectively, more and more enterprises have realized that it is quite important to implement the lean management of spare parts. There is no doubt that the lean management mode will be imperative in the field of spare parts management.

\section{The overview of spare parts lean management}

The development of lean management is based on Toyota's definition which called "just-in-time (JIT)" initially. This concept can be regarded as an operation mode to eliminate waste production continuously, which can satisfy the development goals of the enterprise [3]. Lean management mainly includes two aspects, "streamlined" and "beneficial". Lean management can not only reduce nonrenewable resources such as capital investment and resource, but also improve the economic benefit.

The lean spare parts management is a kind of enterprise management mode which is used to minimize the occupation of production resource and reduce the operating costs. On the one hand, this management mode highlights that it controls the spare parts consumption, ensures enough spare parts inventory, reduces the downtime due to lacking of spare parts; On the other hand, in order to reduce the inventory fund and liquidity as much as possible, this management mode also encourages to keep reasonable inventory quantity of the spare parts.

In recent decades, many international companies are starting to implement the lean management mode. At the same time, a large number of research achievements have been achieved in this field. For instance, Pedro José [4] has studied the relationship of the lean management, the supply chain management and the sustainability. Jared Ross [5] has discussed the successful lean management cases in the 
field of automobile manufacturing industry, the post office and health-care. The researcher also highlighted that it was quite significant to convene all the employees to involve in the project. Combining with the lean management theory, $\mathrm{Xu}$ [6] has studied the lean management approach which was suitable for the power supply enterprises. Wei [7] has researched the applications about the after-sale lean spare parts inventory management mode in Automobile Corporation. $\mathrm{Xu}[8]$ has not only evaluated the spare parts safety inventory and purchase plan but also developed the model of spare parts inventory management with the method of normal distribution.

\section{Research status of lean spare parts management}

Some certain classification work is needed to get the targeted features of every spare part. As is known to all, the main purpose of the spare parts management should find an appropriate balance among supply, working capital and operating costs. Different spare parts management strategies are suitable for different kinds of spare parts with different characteristics and supply chain processes. As a result, the spare parts classification methods have been widely used in the lean management so far.

The abroad lean spare parts management classification approach. The spare parts classification method is implemented earlier abroad. In the $1960 \mathrm{~s}$, according to the properties of repairable, Allen and D'esop [9] had divided the spare parts into two categories roughly. Since then, in order to meet the actual needs, much more detailed spare parts classification methods have been raised. For example, R.Dekker [10] had divided the spare parts into critical and non-critical demand ones, and suggested to keep certain inventory for the critical parts. Considering the constraint of spare parts inventory, outage cost, safety problem, environmental goals, maintenance strategy and logistics, Braglia [11] had divided the spare parts into different categories and Cohen [12] had divided the spare parts according to urgent needs or just common demand.

The domestic lean spare parts management classification approach. The domestic researches on the spare parts classification are mainly using $\mathrm{A} / \mathrm{B} / \mathrm{C}$ classification methods. For instance, Jin [13] had developed a method to divide the spare parts by the $\mathrm{A} / \mathrm{B} / \mathrm{C}$ classification, combining with another classification according to their price, delivery time, quantity and lifetime. According to the cost proportion of each variety part, Liang and Wang [14] had divided the total parts into three categories $(\mathrm{A} / \mathrm{B} / \mathrm{C})$ roughly, and then considered the use of fuzzy decision-making method to carry out a comprehensive evaluation of the detailed classification. Guo [15] had divided the spare parts into four categories (A/B/C/D) based on the degree of impact to the production, the regular pattern of failure and supply channels efficiency. Cui and Luo [16] had defined the repair availability, critical degree and economical index as the classification criteria, and classified the spare parts into $\mathrm{A} / \mathrm{B} / \mathrm{C}$ categories with the method of analytic hierarchy process.

\section{The model of lean spare parts Inventory management}

The mathematical model of spare parts inventory management can be established to keep the inventory scientific, so that spare parts can just meet with the maintenance demands without waste based on the lean model. According to actual production experience and spare part requirement, we have divided the total inventory into four categories. They are consumable parts, wear parts, insurance parts and accident parts as shown in Table 1 respectively.

Table 1. Spare parts classification methods

\begin{tabular}{|c|c|c|c|c|}
\hline Classification & Characteristic & $\begin{array}{c}\text { Target } \\
\text { Number }\end{array}$ & $\begin{array}{l}\text { Target } \\
\text { value }\end{array}$ & Risk \\
\hline Consumable parts & $\begin{array}{l}\text { The probability of fault is } 100 \% \text { and the frequency of } \\
\text { replacement is very high.(e.g. the frequency of replacement less } \\
\text { than } 1 \text { year) }\end{array}$ & $45 \%$ & $15 \%$ & $100 \%$ \\
\hline Wear parts & $\begin{array}{l}\text { The probability of fault is } 100 \% \text {, but the frequency of } \\
\text { replacement is not so high. (e.g. the frequency of replacement } \\
\text { more than } 1 \text { year) }\end{array}$ & $35 \%$ & $25 \%$ & $100 \%$ \\
\hline Insurance parts & $\begin{array}{l}\text { The probability of fault is from } 20 \% \text { to } 100 \% \text {, and will be } \\
\text { used after } 5 \text { years. }\end{array}$ & $15 \%$ & $30 \%$ & $95 \%$ \\
\hline Accident parts & $\begin{array}{l}\text { Normally, these parts will never be used except the reason of } \\
\text { quality, design, accident and so on. }\end{array}$ & $5 \%$ & $30 \%$ & unknown \\
\hline
\end{tabular}

The lean inventory management model of consumable and wear parts. Assuming that the lead time is a constant for each spare part, we have established the safety stock formula for consumable parts and wear parts which are shown in formula (4). These formulas [17] provide an important reference to the structural optimization for the inventory work.

$$
\begin{gathered}
\bar{d}=D / 365 \\
R=\bar{d} \times L+S \\
Q=\bar{d} \times T(T \geq L)
\end{gathered}
$$




$$
S=z \sqrt{\sigma_{d}{ }^{2} \times \bar{L}+\sigma_{L}{ }^{2} \times \bar{d}^{2}} \approx z \times \sigma_{d} \times \sqrt{\bar{L}}
$$

Among the formulas above, $\boldsymbol{D}$ represents the annual demand quantity, $\boldsymbol{R}$ represents the reorder point, $\overline{\boldsymbol{d}}$ represents daily average demand quantity, $\boldsymbol{L}$ and $\overline{\boldsymbol{L}}$ are on behalf of the lead time and the average lead time respectively, $\boldsymbol{S}$ represents the safety stock, $\boldsymbol{Q}$ represents the quantity of replenishment, $\boldsymbol{T}$ represents order interval,
$\boldsymbol{Z}$ represents the number of standard deviations under a certain service level, $\sigma_{d}$ and $\sigma_{L}$ are respectively represent the standard deviation of daily average demand quantity $\overline{\boldsymbol{d}}$ and the lead time $\boldsymbol{L}$. According to the inventory management model, we can get the scientific stock data, see in the table 2 .

Table 2. Example of spare part inventory model

\begin{tabular}{ccccccc}
\hline Material Number & Description & $\overline{\boldsymbol{d}}$ & $\mathrm{L}$ & $\mathrm{S}$ & $\mathrm{R}$ & $\mathrm{R} 0$ \\
\hline MCNP999920005687 & Sucker & 0.1232877 & 120 & 0 & 15 & 20 \\
F303381075730 & Silencer & 0.0191781 & 120 & 0 & 3 & 4 \\
MCNP999940003448 & Pressure switch & 0.0821918 & 50 & 0 & 5 & 6 \\
QEV111AHJWCR & Pressure switch & 0.0191781 & 120 & 0 & 3 & 5
\end{tabular}

According to the warehouse inventory model above, the spare part purchase model shows in figure 1. Figure 1 shows the relationship between inventory and consumption. When the inventory falls to the reorder point $\mathrm{R}$, it creates purchase order on a predetermined quantity $\mathrm{Q}$. The inventory level continues to decline during the lead time, and reaches safety stock. At the same time, the purchase spare parts come and the inventory level will rise. This model mainly relies on the control of reorder point $\mathrm{R}$ and order quantity $\mathrm{Q}$ to meet the best demand of inventory and the lowest total cost.

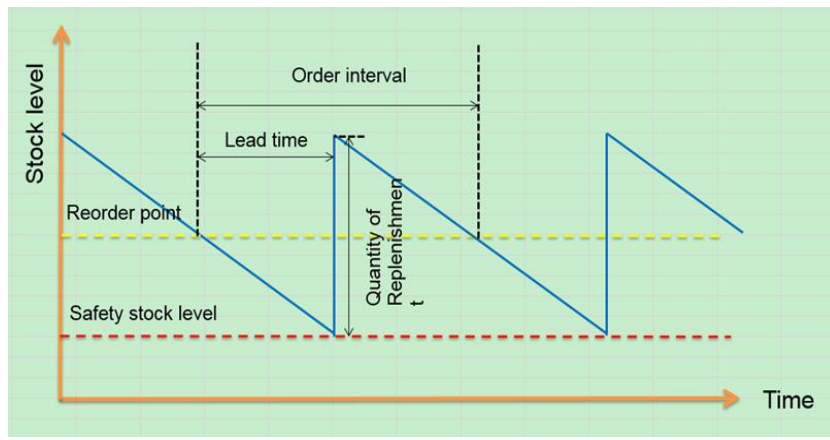

Figure 1. Relationship between inventory and consumption.

The lean inventory management model of insurance parts and accident parts. The Calculation model of the reorder point, the quantity of replenishment and the safety stock for the insurance parts and accident parts are shown in formula (5) to formula (7).

$$
\begin{aligned}
& \boldsymbol{R}=1 / 2 \\
& \boldsymbol{Q}=1 / 2 \\
& \boldsymbol{S}=0 / 1
\end{aligned}
$$

where, $\boldsymbol{R}$ represents the quantity of replenishment, $\boldsymbol{Q}$ represents the quantity of replenishment, $\boldsymbol{S}$ represents the safety stock.

\section{Methods of lean spare parts management}

The lean spare parts management based on supply chain. Under the policy of the company to implement the lean management, we have established a new lean spare parts management model shown in Figure 2, which is based on the supply chain, such as controlling the procurement process, improving the supplier's quality management methods, implementing the centralized procurement and some other specific measures combined with the experience of the other large scale manufacturing enterprises spare parts management.

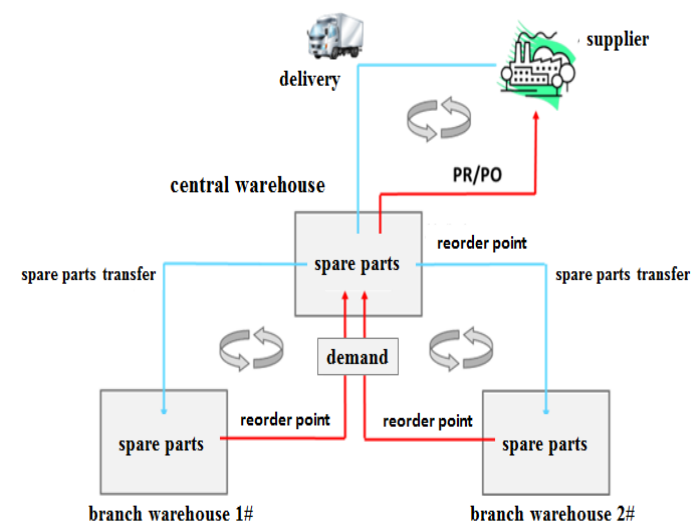

Figure 2. Schematic diagram of lean spare parts management mode based on supply chain.

The central warehouse has put into use after the hardware procurement, personnel training, process specifications and other preliminary preparation. By defining the logistics center as the function orientation, it has improved the cooperation of three maintenance team (factory maintenance workshop, MRA I repair workshop, engine plant maintenance workshop) significantly and 
make contribution to the standardization management mode which consists of centralized procurement, concentrated delivery and warehousing, distribution and centralized management. In addition, the measures have played a positive role in saving spare parts procurement costs and reduce spare parts inventory funds.

Central warehouse takes the advantages of centralized management for spare parts. Large amounts of spare parts stocks of brand-warehouses have been transfer to central warehouse, which optimizes warehouse stock quantity and stock value. The process of brand-warehouses' spare parts transferring to central warehouse shows in figure 3 .

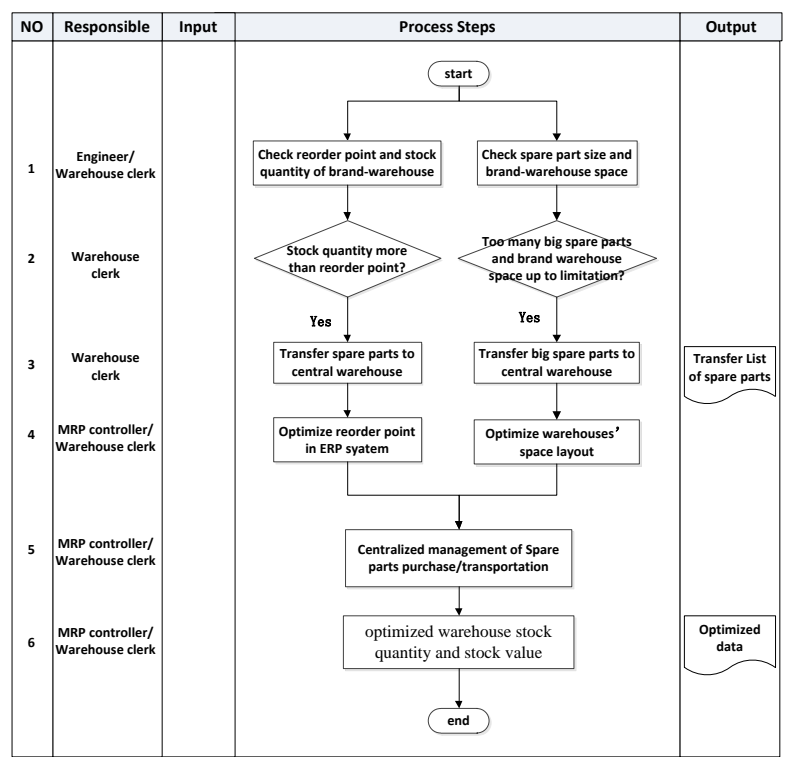

Figure 3. Process of brand-warehouses' spare parts transferring to central warehouse.

The lean spare parts management based on ERP. By building SAP-iPro intelligent ERP information management platform, We have completed the standardization of spare parts procurement processes, spare parts maintenance process and spare parts warehouse management process, the department also has organized the other departments of the enterprise and realized the sharing of information based on the data resource management system which plays a key role in the field of spare parts maintenance and management at the same time. The shortcomings of using Excel spreadsheets cause low efficiency, high error rate and sharing problems of the information, which has been solved by using the ERP information platform. There is no doubt that the implement of ERP system not only makes the company adapt to the demand of the modern enterprise better but also enhances the company's competitiveness with the modern management mode.

Up to now, the total cargo value of the ten branch warehouses and one central warehouse is about 2.25 billion RMB and involves about 33603 kinds of different spare parts. The SAP- iPro system and SAP-cbFC system have successfully been used in the management. In addition, combined with the spare parts maintenance demand and management requirements, the engineers of central maintenance department have developed spare parts management system software independently. And it has been realized to run on the tablet PCs, mobile phones and so on. This software realizes either the real-time spare parts order status or the key spare parts inventory information by the integration of information and data, the real-time spare parts inventory information can be reflected accurately, which facilitates the work of the related departments greatly. Figure 4 shows SAP-iPro and independently developed system for spare part management.

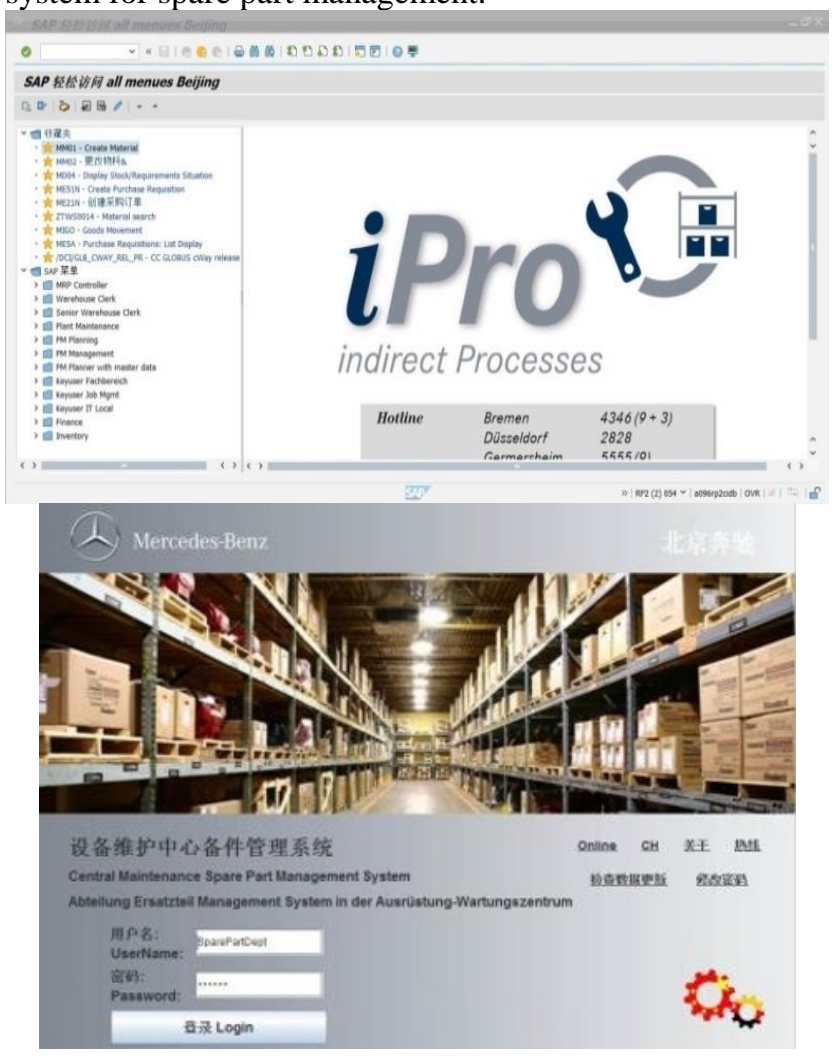

Figure 4. SAP-iPro and independently developed system for spare part management.

The lean spare parts management based on integrating repeated materials. In an optimal situation, different materials should have different type number, order number and the supplier number; the same kind of material must use the unified material information. But as a result of the practical work of variability and material information management is not normative, which generates a lot of repetition of material. The repeated material means the same kind of materials with different material numbers, each material information may be the same or different.

According to the feedback of MRP Controller and warehouse management personnel, material attribute identification is mainly composed of type number and order number, the possibility of repeat materials are summarized as follows.

1) Type number and order number are the same, but the material number is not the same, such as the following table 3

2) Type number and order number are filled in system without standard, maybe they are inclusion relation, such as "6005-2RSH" and "SKF:6005-2RSH".

3 ) Symbols of type number and order number are not uniformed, such as "6005-2RSH" and "6005-2RSH". 
There may be "-", "/", "_" and " ", which are mixed but their main contents are the same.

Table 3. Example of repeated materials

\begin{tabular}{cccccc}
\hline Material Number & Type Number & Order Number & Description & Manufacture & Supplier \\
\hline MCNP9920002889 & $6005-2 \mathrm{RSH}$ & $6005-2 \mathrm{RSH}$ & Bearing & SKF & AOEHANG \\
MCNP9980003928 & $6005-2 \mathrm{RSH}$ & $6005-2 \mathrm{RSH}$ & $\begin{array}{c}\text { GROOVEDBALL } \\
\text { BEARING }\end{array}$ & SKF & GUEDEL
\end{tabular}

According to the characteristics of the above repeated material, an edit distance similarity algorithm is used for accurately and quickly finding all the duplicate data in the system.

Edit distance [18]: the edit distance between two strings $r$ and $s$ defines as ed(r, s) or $\operatorname{ED}(r, s))$, in which three kinds of editing operation (deleting, inserting or substituting a single character string) are used to make string $r$ change into string $\mathrm{s}$. The similarity between string $\mathrm{r}$ and $\mathrm{s}$ depends on how many steps of the editing operation. The fewer steps, the more similar.

For instance, string $\mathrm{r}=$ "abcd" and string $\mathrm{s}=$ "abd", ed $(\mathrm{r}, \mathrm{s})=1$.

Standardized edit distance: the standard edit distance of string $\mathrm{r}$ and string s defines as sed as follows:

$$
D[i][j]=\min (D[i-1][j]+1, D[i][j-1]+1, D[i-1][j-1]+\delta)
$$

Among them, if $r[\mathrm{i}]=\mathrm{s}[\mathrm{j}], \delta=0$; otherwise $\delta=1$. The final $\mathrm{D}[|\mathrm{r}|][\mathrm{s} \mid]$ is the edit distance between strings $\mathrm{r}$ and $\mathrm{s}$.

For example, given two strings $s=$ "ser good" and "ser goal", calculate the edit distance between strings $r$ and $s$ by

\begin{tabular}{|c|c|c|c|c|c|c|c|c|c|}
\hline & $\Phi$ & $\mathrm{s}$ & $\mathrm{e}$ & $\mathrm{r}$ & & $\mathrm{g}$ & $\mathrm{o}$ & $\mathrm{o}$ & $\mathrm{d}$ \\
\hline$\Phi$ & 0 & 1 & 2 & 3 & 4 & 5 & 6 & 7 & 8 \\
\hline $\mathrm{s}$ & 1 & 0 & 1 & 2 & 3 & 4 & 5 & 6 & 7 \\
\hline $\mathrm{e}$ & 2 & 1 & 0 & 1 & 2 & 3 & 4 & 5 & 6 \\
\hline $\mathrm{r}$ & 3 & 2 & 1 & 0 & 1 & 2 & 3 & 4 & 5 \\
\hline & 4 & 3 & 2 & 1 & 0 & 1 & 2 & 3 & 4 \\
\hline $\mathrm{g}$ & 5 & 4 & 3 & 2 & 1 & 0 & 1 & 2 & 3 \\
\hline $\mathrm{o}$ & 6 & 5 & 4 & 3 & 2 & 1 & 0 & 1 & 2 \\
\hline $\mathrm{a}$ & 7 & 6 & 5 & 4 & 3 & 2 & 1 & 1 & 2 \\
\hline 1 & 8 & 7 & 6 & 5 & 4 & 3 & 2 & 2 & 2 \\
\hline
\end{tabular}

(a) Standard dynamic program algorithm

$$
\operatorname{sed}(r, s)=1-\frac{\operatorname{ed}(r, s)}{\max \{|r|,|s|\}}
$$

The value of sed is $[0,1]$, sed is closer to 1 , indicating that the more similar between the two strings.

In order to solve the edit distance between strings $r$ and $\mathrm{s}$, the standard dynami c programming algorithm can be used to solve the problem. The time complexity of the algorithm is $\mathrm{O}(|\mathrm{r}| *|\mathrm{~s}|)$, and the space complexity is $\mathrm{O}(\mathrm{min}$ $(|\mathrm{r}|,|\mathrm{s}|))$.

We can use a matrix $D$ with $|r|+1$ rows and $|s|+1$ columns to calculate two strings' edit distance, the initialization of $\mathrm{D}[\mathrm{i}][0]=\mathrm{i}, 0 \leqslant \mathrm{i} \leqslant|\mathrm{r}|, \mathrm{D}[0][\mathrm{j}]=\mathrm{j}, 0 \leqslant \mathrm{j} \leqslant|\mathrm{s}|$, then we can make iterative calculation of $\mathrm{D}[\mathrm{i}][\mathrm{j}], 1 \leqslant \mathrm{i} \leqslant|\mathrm{r}|, 0 \leqslant \mathrm{j} \leqslant|\mathrm{s}|$, according to the following formula:

the standard dynamic programming algorithm. Run the process as shown in the following figure, the final ed $(r, s)$ $=2$, see in figure 5 .

\begin{tabular}{|l|l|l|l|l|l|l|l|l|l|}
\hline & $\Phi$ & $\mathrm{s}$ & $\mathrm{e}$ & $\mathrm{r}$ & & $\mathrm{g}$ & $\mathrm{o}$ & $\mathrm{o}$ & $\mathrm{d}$ \\
\hline$\Phi$ & 0 & 1 & 2 & & & & & & \\
\hline $\mathrm{s}$ & 1 & 0 & 1 & 2 & & & & & \\
\hline $\mathrm{e}$ & 2 & 1 & 0 & 1 & 2 & & & & \\
\hline $\mathrm{r}$ & & 2 & 1 & 0 & 1 & 2 & & & \\
\hline & & & 2 & 1 & 0 & 1 & 2 & & \\
\hline $\mathrm{g}$ & & & & 2 & 1 & 0 & 1 & 2 & \\
\hline $\mathrm{o}$ & & & & & 2 & 1 & 0 & 1 & 2 \\
\hline $\mathrm{a}$ & & & & & & 2 & 1 & 1 & 2 \\
\hline 1 & & & & & & & 2 & 2 & 2 \\
\hline
\end{tabular}

(b) Dynamic program algorithm based on threshold

Figure 5. Edit distance graph for dynamic programming.

By using the edit distance similarity algorithm to analyze the data of spare parts, it can find out all the duplicate materials and process them in the system, so as to further optimize the spare parts inventory value. The result shows that about 16 thousand duplicate materials were found. These duplicate materials are combined as unique material and warehouse inventory is deduced. After 10 months' working on processing duplicate materials, nearly 40 million RMB was saved. Figure 6 shows detail of duplicate materials processing result.

\section{Summary}

Lean spare parts management is a kind of effective operation to minimize the quantity of inventory and reduce operating costs for enterprises, which closely depend on the accurate information, the establishment of the spare parts management database and the other applications of project management tools. As an equipment maintenance and spare parts management department of modern automotive manufacturing enterprise, we have absorbed the lean idea into the enterprise management culture. Practice has proved that not only a new lean mode of spare parts management has been explored but the cost of spare parts purchasing and inventory has been controlled, which makes great 
contribution to the developing of scientific and standard

spare parts management.

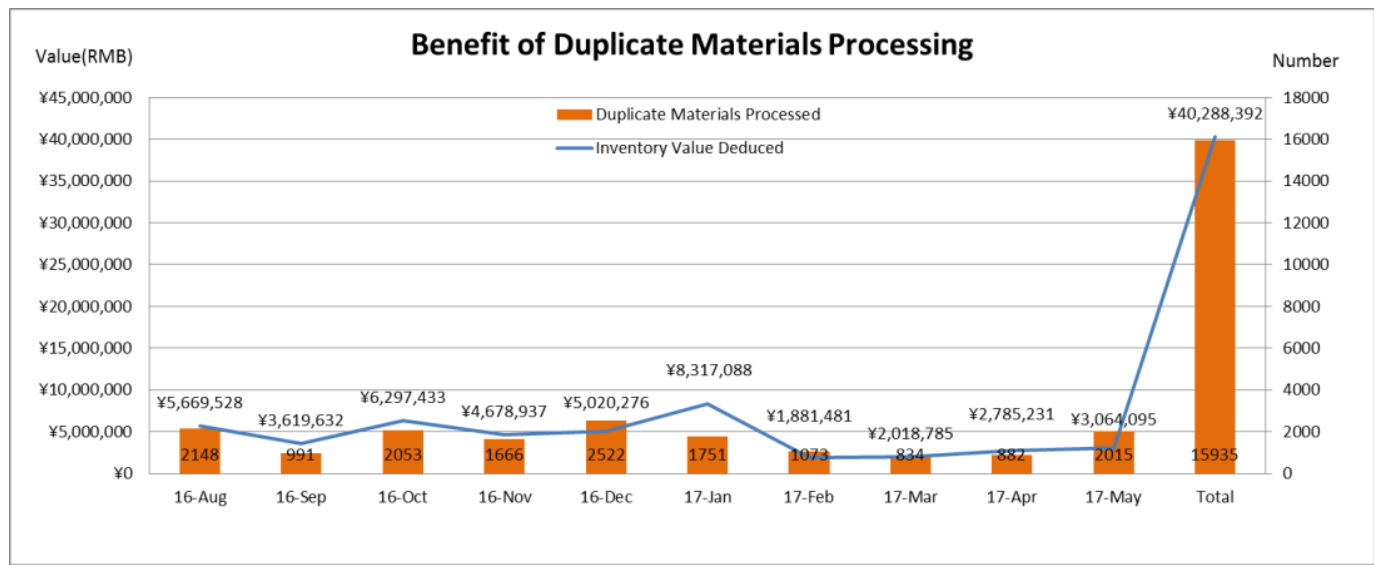

Figure 6. Benefit of duplicate materials processing.

\section{References}

1. DRIESSEN M, ARTS J, HOUTUM G J V. Maintenance spare parts planning and control:a framework for control and agenda for future research [J]. Production Planning \& Control, 2014, 26 (5) , p. 407-426.

2. Zhang Haili. Research and Application of Spare Parts Inventory Optimization Mechod of A Steel Company [D].Zhe Jiang University,2013.

3. Lu Yongming. Research on the inventory management of Toyota Corporation service parts -- the application of lean management concept in service parts inventory management [D]. Nan Kai University,2011.

4. MART NEZJURADO, PEDROJOS Lean management: state-of-the-art and success factors in the adoption process. Evidence from the aerospace sector [J]. 2013.

5. FLYNN J R, VLOK P J. Lean Approaches in Asset Management Within the Mining Industry [J]. Lecture Notes in Control and Information Sciences, 2015, 20, p. 101-118.

6. $\mathrm{Xu}$ Yongteng. Lean management of Spare Parts in Power Supply Enterprise [J]. Guang DongScience and Technology, 2010, 19 (22), p. 82-84.

7. Wei Zhancheng. The Application of Lean Management in Chang He Automotive spare parts' customer service [D]. Nachang University, 2010.

8. Xu Weidong. Spare Parts Inventory Management Model based on Lean Model [J]. The Ten-day of Small and Medium-sized Enterprise Management and Technology, 2015, (3) , p. 36-37.

9. ALLEN S G, D'ESOPO D A. An Ordering Policy for Repairable Stock Items [J]. Operations Research, 1968, 16 (3), p. 669-674.
10. ARONIS K P, MAGOU I, DEKKER R, et al. Inventory control of spare parts using a Bayesian approach: A case study [J]. European Journal of Operational Research, 2004, 154 (3) , p. 730-739.

11. BRAGLIA M. Multi-attribute classification method for spare parts inventory management $[\mathrm{J}]$. Journal of Quality in Maintenance Engineering, 2004, 10 (1) , p. 55-65.

12. COHEN M A, KLEINDORFER P R, LEE H L, et al. Multi-item service constrained ( $\mathrm{s}, \mathrm{S}$ ) policies for spare parts logistics systems [J]. Naval Research Logistics, 2010, 39 (4) , p. 561-577.

13. Jin Xiwan, Ying Jingwen. Research on ABC Classification of Spare Parts Inventory [J]. Journal of East China Institute of Metallurgy, 1997, (1), p. 60-64.

14. Liang Guangtao, Wang Tianhong. Discussion on Classification Method of Spare Parts Inventory [J]. Construction Machinery Technology and Management, 1999, (5), p. 28-29.

15. Guo Zhiming, Yan Hongsen, Chen Shihua, et al. Research on Spare Parts Inventory Control [J]. Computer Integrated Manufacturing Systems, 2003, 9 (6), p. 1028-1032.

16. Cui Nanfang, Luo Xue. ABC Classification Model Based on AHP for Maintenance Spare Parts [J]. Industrial Engineering and Management, 2004, 9 (6), p. 33-36.

17. $\mathrm{Wu}$ Peili. The research of spare parts inventory management [D]. Harbin Institute of Technology, 2010, p. 14-18.

18. Yang Jian. Research on Top-k String Similarity Search Based on Edit Distance [D]. Harbin Institute of Technology, 2015, p.10-13. 